\title{
Revisitando a marca de plural na concordância de número: novos dados do português brasileiro e do francoprovençal antigos
}

\section{The plural marker within the Noun Phrase revisited: new data from Brazilian Portuguese and Old Francoprovençal}

\author{
Maria Antonieta A. M. Cohen* \\ Universidade Federal de Minas Gerais, Belo Horizonte, MG, Brasil \\ Simone Fonseca Gomes ${ }^{* *}$ \\ Universidade Federal de Minas Gerais, Belo Horizonte, MG, Brasil
}

\begin{abstract}
Resumo: Neste texto são apresentados e discutidos dados originais e fidedignos do português brasileiro do século XIX e do francoprovençal, contemporâneo e antigo, como uma contribuição para o encaixamento da questão da concordância de número no sintagma nominal português numa matriz românica. Esses dados registram a participação do -s de plural, típico das línguas românicas ocidentais, em processos de mudança linguística, a saber, supressão, sonorização e ressegmentação e vêm completar informações para adequado enquadramento da questão. Ressalta-se a relevância das abreviaturas na análise linguística nos dados do século XIX. A utilização de dados originais e confiáveis reveste-se da maior importância para análises de sincronias linguísticas pretéritas.
\end{abstract}

Palavras-chave: -s de plural. Concordância de número. Dados confiáveis. Português mineiro. Línguas românicas.

\begin{abstract}
New original and reliable data from both 19th Brazilian Portuguese texts and $16 \mathrm{C}$ Francoprovençal and contemporary language are presented and discussed in this text, as a contribution to the number agreement studies of Brazilian Portuguese, by embedding the issue within a Romance perspective. These data show the role the plural -s marker plays in language changes such as voicing, deletion and resegmentation in Galo Romance and come to fulfill gaps for an adequate understanding of the question. The relevance of the abbreviated forms to linguistic analysis is also shown as well as the use of original and reliable data in the search within old stages of languages.
\end{abstract}

Keywords: Plural -s. Number agreement. Reliable data. Portuguese of Minas Gerais. Romance languages.

\section{A COLOCAÇÃo DA QUESTÃo}

Neste texto são apresentados e discutidos, dentro de uma perspectiva românica, dados relativos à participação do -s como morfema de plural nos

\footnotetext{
* Professora titular de Filologia Românica, Faculdade de Letras da UFMG, Belo Horizonte, MG, Brasil; tilah@letras.ufmg.br

** Professora da Área de Estudos Diacrônicos, Faculdade de Letras da UFMG, Belo Horizonte, MG, Brasil; simonefrancais@gmail.com
} 
sintagmas nominais do português e de uma língua galo-românica, o francoprovençal. O português brasileiro contemporâneo é o ponto de partida da discussão, embora não explorado aqui, e o francês é mencionado para melhor enquadramento românico da questão. Os dados do português brasileiro remontam ao século XIX; os do francoprovençal datam do século XVI e de uma variante contemporânea da língua.

O fenômeno que nos interessa é o da participação do -s de plural, típico das línguas românicas ocidentais, em processos de mudança linguística, configurando-se como parte de um drift românico, já por nós discutido em trabalhos anteriores (Cohen, 2002).

Os aspectos que exploraremos são, nessa perspectiva, os que no português brasileiro atual se observam no Sintagma Nominal (SN), quando o -s se mantém no determinante, mas pode ser eliminado nos nomes que define como em [s [sN As menina $\varnothing$ bonitaØ ]não dançaru hoje]. É esta uma regra variável no português brasileiro contemporâneo.

O encaixamento da questão numa perspectiva românica e histórica pode lançar alguma luz sobre o que se passa atualmente no português brasileiro, no sentido de que outra(s) língua(s) românica(s) também sofreu/ram a queda do -s de plural no Sintagma Nominal (SN) na primeira posição do SN, indo mesmo além do estágio de evolução da mudança no português brasileiro: o -s de acusativo plural latino, que vem a ser a marca do plural dos nomes nas línguas românicas ocidentais, é eliminado no francês, não só dos substantivos, mas também dos artigos definidos, passando a marcação de plural a ser veiculada pelas vogais. O -s ainda existe na escrita. Assim:

Quadro 1- Português e francês em relação ao latim.

\begin{tabular}{|c|}
\hline Port. \\
\hline Illos $>$ os $[$ os $\sim$ us], les [le], \\
\hline Lat. $>---{ }^{2}$ \\
\hline
\end{tabular}

Em termos de manutenção do -s de plural, o português é mais conservador do que o francês, que já mudou a marcação do plural para o sistema vocálico. Ou seja, a marca de plural é mantida no SN, mas não é mais expressa pela consoante -s. No português o -s ainda carrega a noção de plural de todo o $\mathrm{SN}$ e até de toda a sentença, como em (A):

(A) $[s[s \mathrm{~s}$ As menina $\varnothing$ bonita $\varnothing]$ não dançaru hoje]

(B) $[\mathrm{s}[\mathrm{sN}$ Os meninoØ bonitoØ] não dançaru hoje $]$

Independente do gênero, masculino ou feminino, o -s de plural se mantém no elemento que ocupa a primeira posição do $\mathrm{SN}$ no português brasileiro ${ }^{1}$.

No português brasileiro, a concordância variável de número no sintagma nominal (em que o -s é a marca de plural) vem sendo objeto de estudos, principalmente na linha da sociolinguística variacionista, em trabalhos como os de Naro e Scherre, reunidos em Origens do Português Brasileiro (2007), dentre outros. Eles tratam da concordância variável de número Verbo/Sujeito (Cf. "eles ganham demais da conta / eles ganha demais da conta;" da concordância variável de número entre os elementos da sintagma nominal ("os fregueses/as codorna, as porta aberta" e da

\footnotetext{
${ }^{1}$ Naro e Scherre (2007, p. 38 e ss.) tratam da questão em termos de posição linear e não propriamente da categoria deste elemento.
} 
concordância variável de número no sintagma predicativo ("as coisas tão muito caras, né?/as coisa tá cara"). Nosso foco aqui restringe-se à concordância variável de número entre os elementos do $\mathrm{SN}$, pois é neste caso que o -s desempenha um papel, como a marca explícita de plural, o foco de nosso interesse.

Nos anos 1940, 1950 também registrou-se essa ausência de concordância no português brasileiro (Melo, 1946; Silva Neto, 1950), tanto na língua portuguesa da época no Brasil, como em períodos pretéritos da constituição do português brasileiro. Melo (1975 [1946]) advoga em favor de uma influência africana sobre o português no Brasil principalmente na morfologia e cita tanto as desinências de plural que "rareiam", segundo ele, e também a ausência da concordância verbal.

Naro e Scherre (2007) após longa argumentação e análise dentro do modelo variacionista e também do enquadramento histórico da questão são enfaticamente a favor do encaixamento dessas questões como "heranças românicas e portuguesas arcaicas e clássicas e não modificações mais recentes advindas das línguas africanas, que vieram para o Brasil com seus povos escravizados e subjugados, ou das línguas dos povos ameríndios que já aqui se encontravam [...]" (Naro; Scherre, 2007, p. 17).

Comprovam a existência desses fenômenos no português europeu atual e também no português medieval:

\begin{abstract}
A visão da concordância variável como sendo um fenômeno radicalmente não-europeu é refutada pelos dados aqui, os quais mostram que a concordância variável tanto no português europeu falado hoje quanto no português medieval exibe as mesmas características estruturais fundamentais encontradas no português moderno falado no Brasil (Naro; Scherre, 2007, p. 65).
\end{abstract}

Em Cohen (2002) avançamos a questão trazendo dados do judeu-espanhol ocidental, língua de imigrantes na Amazônia brasileira, em que o -s marcador de plural também está envolvido em processos de mudança linguística, dentre outros, a reanálise (Harris; Campbell, 1995). Um desses ambientes da queda do -s acontece na palavra "Dió" ('Deus') em que o -s, que existe no espanhol "Diós" e no português Deus é suprimido no dialeto judeu-espanhol. Essa ausência é percebida pelos falantes, que a justificam, segundo Bentes (1981), explicando que o Deus hebreu é único e que a palavra que o expressa não poderia ter um -s de plural. Vê-se, portanto, que esse -s poderia ter sido reanalisado como plural, mesmo sem ser etimologicamente um plural. Outra hipótese é a de que ele teria sido suprimido por razões internas à língua, acrescido o fator da história externa mencionado. A ordenação dessas mudanças, a saber, reanálise, esvaziamento gramatical, supressão terá de ser melhor elaborada e estabelecida. (Cf. Cohen, 2002 para detalhes). Importa analisar a supressão do -s final vinculada a outros processos de mudança

Para compor este quadro românico parcial, em que o -s em posição final de palavra é envolvido em mudanças, trazemos em 2 dados originais do português brasileiro do século XIX, e em 3 dados também originais de uma variante do francoprovençal atual no domínio francês (Cf. Gomes, 2019) e do francoprovençal do século XVI da região da cidade francesa de Grenoble, a região Rhône-Alpes. Não chegamos a nos aprofundar na questão da concordância nominal propriamente, mas nos restringimos ao tratamento do -s morfema de plural e suas variantes.

Exploramos dados do francoprovençal em que a marca de plural, que ocorre em fronteiras de palavras, se sonoriza, chegando a se incorporar à palavra seguinte. 
Nas línguas galo-românicas a perda generalizada do -s na oralidade encontra-se em estágio avançado em relação ao português, como vimos acima, configurando uma reorganização do sistema de marcação de número na língua, no qual os determinantes desempenham papel crucial, expressando a informação de número.

Esses fatos/análises são relevantes para a discussão da hipótese da deriva românica e portuguesa em fenômenos do português brasileiro. Em Cohen (2002, p. 85-87) fizemos uma incursão na história românica para mostrar que a questão da queda ou eliminação do -s em final de palavra era um fenômeno existente na língua latina e que sua ausência e/ou variação nas línguas românicas pode ser descrito e explicado devido a causas internas e externas.

\section{DADOS DO PORTUGUÊS BRASILEIRO DO SÉCULO XIX}

Em documentos do português mineiro do século XIX, coletados e criteriosamente editados por Chaves e Alkmim (org.) (2002) (Cartas pessoais do século XIX. Acervo Monsenhor Horta. ICHS, UFOP, Mariana, 2002), preciosos casos de ausência de concordância nominal de número são registrados. A localidade de onde procedem os documentos é São Caetano, atualmente o distrito Monsenhor Horta, de Mariana, em Minas Gerais. Os dados editados são privilegiados por serem datados, localizados e autógrafos. Pode-se identificar o emissor e o destinatário. Os documentos examinados datam das décadas de 1880 e 90.

Como se verá, revelam também algo relativo ao tipo ou gênero textual que possa favorecer a ausência da concordância e vêm reforçar a importância do conhecimento da língua antiga para melhor entendermos a língua contemporânea, no caso, o fenômeno da marcação de plural e a concordância de número no sintagma nominal.

Quanto à forma e conteúdo: trata-se de 316 "cartas", bilhetes, registros de encomendas feitas provavelmente em uma venda, em que os moradores dessa pequena localidade faziam suas compras: material de costura, linhas tecidos, rendas e também outros, típicos da vida rural, cordas, tachas e curiosamente material para confecção de sepulturas, caixões, mortalhas, incluindo os ingredientes para as quitandas a serem servidas nos velórios, compra e venda de gado, registro de dívidas, de heranças. Revelam muito da vida quotidiana dos moradores dessa pequena localidade mineira no século XIX. O pagamento das compras não era imediato, mas efetuado muito tempo depois da encomenda. As cartas registram também os acertos das contas, também datados: uma encomenda de fevereiro de 1894 foi paga em agosto do mesmo ano; encomenda de 1891, paga por outras pessoas, talvez um descendente do comprador, em 1894.

Trazemos aqui uma amostragem do que pode ser encontrado neste acervo, em termos da marcação do plural no sintagma nominal do português.

Veja-se que os dados abaixo registram tanto a ausência do -s de plural, em I., à semelhança dos dados do português brasileiro contemporâneo citados em 1.0, quanto sua presença, em II, também como no Português Contemporâneo, apresentam, no entanto, alguns aspectos dignos de atenção ${ }^{2}$. Apresentamos na

${ }^{2}$ Marcamos a ausência do -s de plural com o símbolo $\varnothing$, e negritamos o -s que se realiza. 
sequência o fac-símile do documento analisado.

I. Ausência da marca de plural no substantivo

(1) " $6 \mathrm{~m}^{\mathrm{t} \emptyset}$. de murim"

(2) " 3 "de chita roxa escura"

(3) "Dezejolhe ${ }^{\text {tas }}$. felicidade Ø"

(4) "... 6 metro $\varnothing$ de murim do milhor q' tiver"

(5) “... 3 metroØ de chita bem róxa...”

(6) " aceite minhas recomendaçãoØ pa Vm.ces. todas"

(7) “...2 1 la $^{\mathrm{ta}}$ de cêra"

(8) "2 PeSsaØ de renda"

(9) "4 $1 / 5 \mathrm{~m}$ tø. de murim"

(10) "2 carretelØ de retrós preto"

II. Presença da marca de plural no substantivo

(11) "2 Maços de tachas"

(12) "3 Novellos de linha e 2 fivellas"
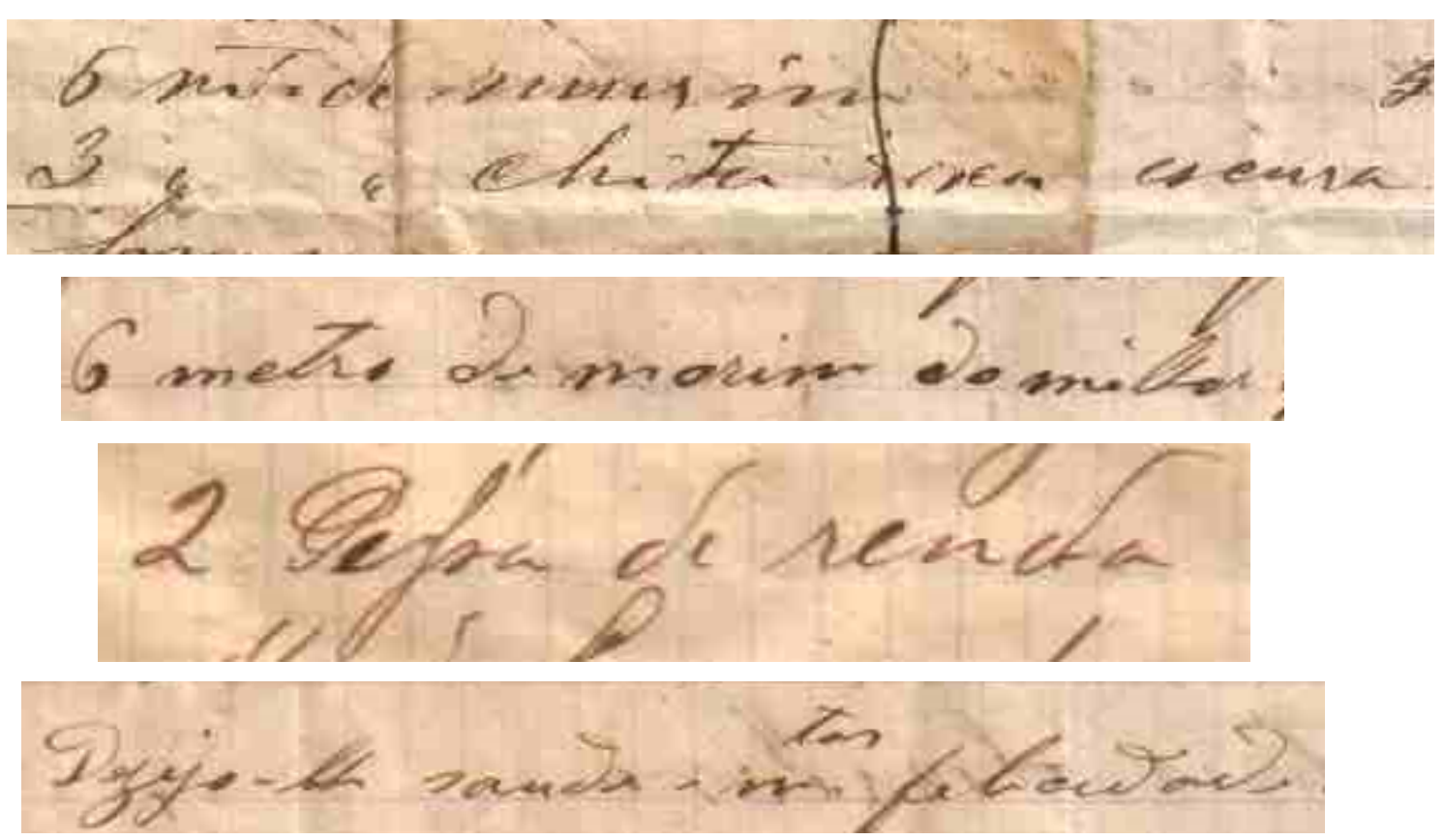

Fonte: Chaves; Alkmim, 2002.

Figura 1 - trechos do documento.

Vamos abordar em primeiro lugar os itens que ocupam a posição do determinante, para depois comentarmos sobre os nomes que se lhe seguem. Observe-se que em 8 das 10 ocorrências do grupo I a posição inicial é preenchida por números, $6,3,6,3,2,2,41 / 5,2$, e em apenas 2 casos por itens lexicais, a saber, minhas (por extenso) e $\mathrm{m}^{\text {tas }}$ (abreviada).

Nos estudos sobre o português brasileiro contemporâneo é lugar comum se afirmar que a posição linear é a variável mais importante a marca de plural nos SNs e que a primeira posição favorece variavelmente a presença da marca explícita de 
plural ${ }^{3}$. Assim, em (“os fregueses/as codorna, as porta aberta” (Scherre, 2007, p. 50), a marca do plural acontece no determinante, que é o $1^{\circ}$. elemento do $\mathrm{SN}$.

Nos exemplos de (1) a (10) estamos considerando que os primeiros elementos do SN, sejam numéricos ou lexicais, são marca explícita de plural: tanto no caso dos números, que carregam em si a noção de pluralidade, quanto dos outros dois, minhas e muitas, nesses dois claramente devido ao -s. A ideia de plural está contida em todas essas ocorrências. Observe-se que o elemento que ocupa a $1^{\text {a }}$. posição pode ser abreviado, como $\mathrm{m}^{\text {tas }}$.

Passemos ao segundo elemento, que são substantivos. Como se pode ver, os dados de (1) a (10) registram a ausência da marcação do substantivo com o -s de plural, em ocorrências em que se espera o plural devido à presença dos números 6,3 , 2 ..., que carregam em si a noção de pluralidade ou à forma plural do pronome e do adjetivo.

Essa ausência do -s nos nomes verifica-se tanto nas formas escritas por extenso, como metro $\varnothing$, carretel $\varnothing$, peSsaØ, quanto nas formas abreviadas, em que predomina o substantivo metro, abreviado com o -t sobrescrito: $\mathrm{m}^{\mathrm{t} \varnothing}$, ao lado de lata, abreviado como $1^{\text {ta }}$, com a sílaba -ta sobrescrita.

A palavra metro aparece 2 vezes por extenso em (4), não flexionada para número: "...6 metro de murim..." e (5) "3 metro de chita...", e 3 vezes abreviada, em (1) "6 $m^{t}$ de murim...", (2) "3 $m^{t}$ de chita roxa escura, e (9) "4 1/5 $m^{t}$ de murim, também não flexionada para número.

Em (3) "Dezejolhe $\mathrm{m}^{\text {tas }}$. felicidade e em (6) "aceite minhas recomendação pa Vm. ${ }^{\text {ces. }}$ todas", o elemento que ocupa a $1^{\text {a }}$ posição é o adjetivo muitas, abreviado e flexionado no feminino plural: $\mathrm{m}^{\text {tas }}$. $\mathrm{O}$ nome, em $2^{\mathrm{a}}$. posição, não marca plural: felicidadeØ" e recomendação.

Interessante a marcação de plural que ocorre em (6), em “...pa . Vm. ${ }^{\text {ces }}$ todas". O elemento que marca o plural e o feminino é posposto ao núcleo, ocupado por um pronome de tratamento flexionado no plural.

Nesta listagem predominam os substantivos relativos a medidas e embalagens: metro, peSsa carretel, lata. Metro e lata aparecem abreviados e mesmo a abreviatura não marca plural verifica-se.

Em II, em (11) "2 Maços de tachas" e (12) "3 Novellos e fivellas, o primeiro elemento é um número, como nos casos de I, e o segundo, um substantivo, que tem o -s de plural. A diferença entre I e II está na marcação do plural nos exemplos de II e sua ausência nos de I.

$O$ que tais dados trazem de novo: em primeiro lugar o registro da concordância variável de número nesta fase da língua portuguesa do Brasil, no século XIX, em uma edição confiável de uma modalidade de língua bem vernacular; nos casos de ausência da concordância ressalta o fato de o primeiro elemento do SN ser predominantemente um número; também a abreviação dos nomes sem a marca de plural esperada, já que o $1^{\mathrm{o}}$ elemento é plural, ressalta dos dados $\left(\mathrm{m}^{\mathrm{t}}, \mathrm{lt}^{\mathrm{a}}\right)$.

Embora a abreviatura, por sua natureza redutora, não precise marcar número

\footnotetext{
${ }^{3}$ Cf. Scherre (1988), que comprova o entrelaçamento de outras variáveis além da posição linear no
} tratamento da concordância de número. Não detalharemos essa análise. 
ou gênero, veja-se $\mathrm{m}^{\text {tas }}$, em que o número e o gênero gramaticais são marcados na abreviatura e $1^{\text {ta }}$, em que o gênero feminino também o é, e $\mathrm{Vm}^{\text {ces }}$, que marca o plural na forma abreviada. Donde, também nas formas abreviadas, no $1^{\circ}$ elemento ou não, registra-se a variação da presença/ausência do -s. Mesmo sendo em número reduzido, esses dados indicam que o fenômeno tem uma sistematicidade na língua do século XIX. A consideração das abreviaturas na análise linguística foi relevante para a identificação de generalizações.

Soma-se a esses o tipo de palavra que predomina nessas listagens: o número e substantivos referentes a medidas e embalagens, sugerindo que o tipo semântico possa ser uma variável a ser levada em conta nas análises do fenômeno. Esse tipo de palavra há de ocorrer num determinado tipo de texto (lista, enumeração), além de outros contextos mais comuns que também constam desse pequeno universo de sentenças analisado.

Esses resultados vêm ao encontro do que Scherre (2007, p. 40) coloca sobre os fatores que são relevantes (estatisticamente) na escolha das variáveis que atuam na concordância de número "os condicionamentos são bem mais complexos do que se pensava anteriormente", embora ela não esteja se referindo a classes semânticas, tipo textual e abreviaturas, como nós, mas à relação entre posição/classe e relação.

Esses casos revelam características linguísticas das abreviaturas, corroborando o que Chaves (2006) desvela sobre as formas abreviadas: há que se descobrir a sistematicidade de seu uso, uma sistematicidade ${ }^{4}$ presente na língua da época do documento ${ }^{5}$.

Recuando um pouco no tempo, Prado Mendes (2008, p. 124 e ss.) apresenta e analisa dados do português mineiro do século XVIII em que a concordância de número no SN é variável.

Tais análises demandam aprofundamento, mas já indicam (i) existência da variação presença/ausência da marcação de plural no SN português em períodos pretéritos da língua no Brasil ${ }^{6}$, (ii) alguns ambientes que podem favorecê-la.

Nessa subseção procuramos preencher o continuum diacrônico da história da marcação de plural no SN português com dados do século XIX. Os dados e sua análise revelaram que a variação da marcação de plural, do -s e sua ausência, existia no português escrito em Minas Gerais no século XIX. Tal ausência da marcação mostrou-se típica de SNs em que um número plural precede um nome que pertence a um grupo lexical referente a medidas, embalagens e afins, embora não somente. $O$ tipo textual, embora inserido em "cartas", dado seu caráter dialógico, pode ser considerado lista, listagem, enumeração, que pelo tema têm em si contido a ideia de plural.

Passamos, em seguida, a examinar dados de outras línguas românicas, a fim

\footnotetext{
${ }^{4}$ Cf. Borges Nunes, E. Abreviaturas paleográficas portuguesas. Lisboa: FL; 1981, que apresenta uma boa sistematização das abreviaturas paleográficas.

5 Há outros trabalhos que apontam de variadas maneiras para a importância linguística das abreviaturas, Cf. Cohen (2010) e (2016), Chaves e Ramos (2015), Duchowny, Coelho e Coelho (2014), dentre outros.

${ }^{6}$ Segundo Naro e Scherre (2007), Mira Mateus (1954) registra essa variação nos anos de 1950 em Portugal.
} 
de contribuir para construir um quadro românico, mesmo que parcial.

\section{DADOS DO FRANCOPROVENÇAL E DO FRANCÊS}

Segundo Tuaillon (1991) o francoprovençal é uma língua em estado dialetal puro, pois nunca teve uma unificação, nunca tendo chegado a ser língua oficial de uma entidade política. Não foi a língua do rei ("la langue du roi") e nem a da república francesa. Não passou, portanto, pelo processo de gramatização, comum às línguas que se oficializam. Tal situação lhe atribui uma fragmentação e variação ainda não submetidas a uma norma supra, que enquadre as variações existentes num padrão.

Assim, o tema de que nos ocupamos contará com dados de localidades diferentes: do patois Bressan atual, do patois de Saint Martin-de-la-Porte, este falado por três gerações, num espaço de tempo que vai de pessoas nascidas entre $1830 \mathrm{e}$ 1890, de Autrans, bem como dados do século XVI, de Grenoble, e dados gerais do francoprovençal antigo (sem localização), extraídos de Hoyer (1993). Assim é a situação desta língua, o que apresenta uma dificuldade para a coleta de dados orais atuais realmente produzidos por seus semi-falantes.

Passemos à análise do artigo definido nessa língua, que é um dos elementos que ocorre na $1^{a}$ posição do SN. Assim como ocorreu com o francês, essa língua também passou por um processo de perda generalizada do -s marca de plural.

Quadro 2: Artigos definidos no francoprovençal contemporâneo (adaptado de Martin, 2005).

\begin{tabular}{|c|c|c|}
\hline & masculino & feminino \\
\hline singular & lo $(\operatorname{lo}, \operatorname{lou}[\mathrm{lu}]$, le $[\mathrm{l}])$ & la \\
\hline plural & los/ les (lou [lu], lo, lé [le]) & las (le [lə], lé [le], lè $\llbracket \varepsilon])$ \\
\hline
\end{tabular}

Como podemos observar, no sistema geral apresentado por Martin (2005), o -s marcador de plural, embora presente em algumas grafias, não é pronunciado nas diferentes variedades da língua. Trata-se de um fenômeno antigo, como discute Cohen (2002b), já presente em diversos falares desde o século XVI. A diferença entre singular e plural é marcada pelo timbre da vogal, como no francês. Entretanto, diante de palavra iniciada por vogal ocorre o reaparecimento da sibilante $-\mathrm{s}$, articulada [z] ou [3], como observado tanto nos dados do século XVI, como em descrições mais recentes da língua. Vejamos:

(C) Francoprovençal grenoblois do século XVI (Tuaillon, 1996):

Et de forci de frut louz abro eicoissa'uon.

Et-par-beaucoup- de-fruit-les arbres-craquaient. (tradução mot-à-mot)

Et les arbres craquaient sur le poids de leurs fruits. (tradução livre)

lou - art. de. masc. pl., aqui realizado como louz

(D) Francoprovençal bressan século XXI (Gomes, 2019)

Te ne da pô $(\approx)$ zhuzhe léj autrou

Tu ne dois pas juger les autres

léj - art. def. masc. pl.

Nos falares francoprovençais atuais pode-se observar também a perda generalizada da marcação de número nos substantivos e adjetivos. Como afirma 
Martin (2005), a pronúncia dos nomes masculinos é frequentemente idêntica no singular ou no plural. Apenas na região Haute-Maurienne pode-se encontrar falares que conservam a pronúncia do -s. Os nomes femininos, por sua vez, conservam uma distinção fundada no timbre da vogal: -a para o singular e -e para o plural. A perda do -s no feminino também é observada, com exceção da região Haute-Maurienne.

O importante papel do artigo definido, e dos determinantes em geral, na expressão do número pode ser observado em outras línguas galo-românicas, o francês e o occitano. Vejamos a seguir o sistema do francês e do provençal moderno.

Quadro 3: Artigos definidos no francês.

\begin{tabular}{|l|l|l|}
\hline & masculino & feminino \\
\hline singular & le $[$ lə]/1' (diante de vogal) & la / l' (diante vogal) \\
\hline plural & les [le] / [lez] diante vogal & les [le] / [lez] diante vogal \\
\hline
\end{tabular}

Quadro 4: Artigos definidos no provençal moderno (Blanchet, 1999).

\begin{tabular}{|l|l|l|}
\hline & masculino & feminino \\
\hline singular & lou / 1' (diante vogal) & la / 1' (diante vogal) \\
\hline plural & lei / leis (diante vogal) & lei/ leis (diante vogal) \\
\hline
\end{tabular}

Tanto no francês, como no provençal, os nomes são majoritariamente invariáveis, cabendo aos determinantes a expressão do gênero e do número.

Esses sistemas modernos podem ser melhor compreendidos quando consideramos sua evolução histórica. $\mathrm{Na}$ passagem do latim para as línguas românicas, quando ocorre a perda sistemática dos morfemas marcadores de caso, a forma adjunta ille torna-se determinante na medida em que passa a abrigar os traços que não são mais expressos em outras categorias funcionais. No francês e no occitano antigo, o sistema bicasual herdado do latim conservava o caso sujeito (S) e o caso regime $(\mathrm{R})$, no qual o -s marcava tanto o nominativo singular como o acusativo plural para aquelas palavras latinas que faziam o nominativo singular em -s, sem ser este, no nominativo singular, marca de plural.

Quadro 5: Francês antigo (Barra-Jover, 2009).

\begin{tabular}{|ll|l|}
\hline & & masculino \\
\hline singular & $\mathrm{S}$ & li chevaliers < caballarius \\
& $\mathrm{R}$ & le chevalier \\
\hline plural & $\mathrm{S}$ & li chevalier \\
& $\mathrm{R}$ & les chevaliers < caballarios \\
\hline
\end{tabular}

Quadro 6: Provençal antigo (Anglade, 1921).

\begin{tabular}{|ll|l|}
\hline & & masculino \\
\hline singular & $\mathrm{S}$ & lo murs (1. murus) \\
& $\mathrm{R}$ & lo mur (1. murum) \\
\hline plural & $\mathrm{S}$ & li mur (1. muri) \\
& $\mathrm{R}$ & los murs (l. muros) \\
\hline
\end{tabular}

Nos exemplos do francês e do provençal antigos apresentados acima, podemos observar a importância do artigo na distinção entre os casos regime singular e sujeito plural: o artigo marca gênero, número e caso. Esse protagonismo 
do determinante, já atestado na fase arcaica dessas duas línguas, se acentua nos séculos seguintes, resultando em sistemas caracterizados pela drástica redução da morfologia nominal no que tange à expressão do caso e do número, a despeito de terem essas línguas herdado as formas do acusativo plural, marcadas pela presença do -s. O mesmo pode ser postulado no caso do francoprovençal onde também há perda generalizada do -s nos nomes e nos artigos.

Devemos considerar ainda que, no caso do francês, a redução morfológica dos nomes foi bastante acentuada, atingindo inclusive as vogais átonas finais, que também desaparecem na língua. Isso poderia nos levar a pensar que a perda o -s no francês possa estar envolvida em fenômenos morfofonêmicos mais amplos que ultrapassam o tema central do presente texto, qual seja, o -s marca de plural. Por outro lado, tanto o francoprovençal quanto o occitano conservaram as vogais átonas finais, assim como o português e, no entanto, observa-se nessas línguas a queda do -s, generalizada na galo-românia e variável no português. Esse fato reforça a tese da deriva românica enquanto uma força que atua sobre essas línguas, ainda que em cada uma o fenômeno de perda/manutenção do -s tenha nuances e desenvolvimentos próprios.

O estudo dos dados do francoprovençal revelou também o fenômeno de retorno do -s, sob a forma de [z], resultante da sonorização, nos contextos vocálicos, em especial, na primeira posição do SN, como em frp. ant. louz abro [lu'zabro]. O mesmo ocorre no francês e no provençal: fr. les amis [lezami], prov. leis oustau [leyzustau] .Embora a perda do -s marca de plural tenha se generalizado nas línguas galo-românicas, seu retorno no contexto vocálico é um indício de sobrevivência de um -s subjacente ainda carregado do sentido de plural, herança latina das línguas românicas ocidentais. Não seria, então, um acaso, o fato de o -s ressurgir de forma categórica exatamente na primeira posição do $\mathrm{SN}$, posição essa favorecedora da retenção do -s, como vimos no caso do português brasileiro.

No francoprovençal do século XVI, na obra Lo banquet de la Faye de Laurent de Briançon, várias ocorrências do plural masculino e também do feminino do artigo com presença de -z diante de contexto vocálico são registrados. Vejam-se:

(E) lou zenviron :1/2 // louz environ

De tou lou zenviron 7 ; iqui toute g'aye

lou- art. def. masc. pl.

(F) lou zabro: $41 / 3 / /$ louz abro

Et de forci de frut lou zabro eicoifsa'uon.

lou - art. def. masc. pl.

(G) le zautre : 5/6 // lez autre

8 Sa caborna e't pru gran que le zautre ne son

le - art. def. fém. pl.

(H) lou zeichalié : 26 :3 // louz eichalié

Et, l'eicaraboussan permei lou zeichalié

lou- art. def. masc. pl. 


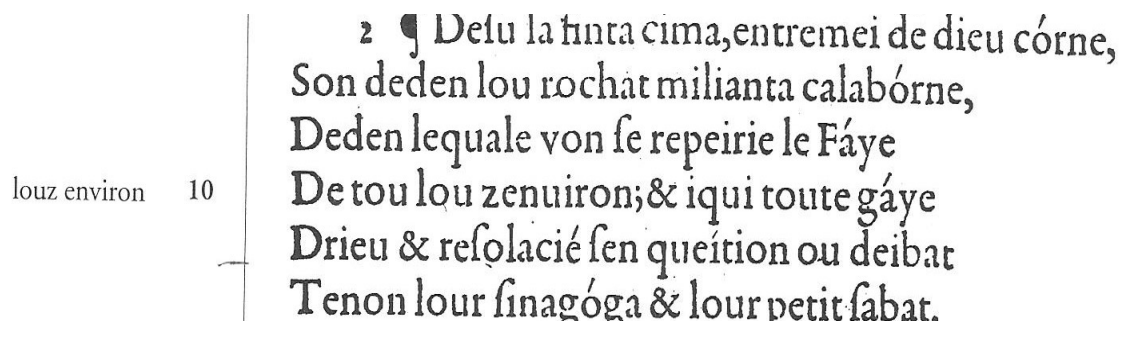

Fonte: Tuaillon, 1996, p. 110.

Figura 2 - Lo banquet de la Faye de Laurent de Briançon.

Veja-se que diante de vogal (E-H) aparece um -z que é analisado por Tuaillon como parte do artigo definido, levando lou a ter uma variante louz e a se propor o seguinte quadro para os artigos definidos dessa época:

Quadro 7: Artigos definidos no francoprovençal do séc. XVI.

\begin{tabular}{|l|l|l|}
\hline & masculino & feminino \\
\hline singular & lo $[\mathrm{lo}]$ & la \\
\hline plural & lou $[\mathrm{lu}] /[\mathrm{luz}]$ diante vogal & le [le] / [lez] diante vogal \\
\hline
\end{tabular}

Em lou rochat 'os rochedos' (linha 8) em que rochat começa por consoante, o-z não parece, já em lou zenviron, em que environ começa por vogal o -z parece já incorporado ao nome seguinte, num fenômeno de ressegmentação e incorporação. $\mathrm{O}$ mesmo ocorre em lou zeichalié $(\mathrm{H})$.

Além desses com o artigo definido, há também outros ambientes em que o -z aparece como com pronomes pessoais que deveriam ter um -s como em "vouz ai veu" - 22: 2, em que "vouz" é um pronome pessoal; ocorre o mesmo com "ele zon": 12:4 // "elez on". Como se vê, a questão do reaparecimento do -s sob a forma de -z não é fenômeno exclusivo do Sintagma Nominal nessa língua, mas atinge também o sintagma verbal.

O processo de reanálise do -s como parte da palavra pode ter como consequência uma alteração do léxico quando a palavra iniciada por -z passa a ser usada no singular, como observou Hoyer (1993):

Zieu - nom; masc. sing.; ( Chap 156) 'oeil' d' un zieu bian tranquilo d'un oeil bien tranquille. Dict . : CO-DE $437 \mathrm{zu}$ sm. oeil. La consonne de liaison du pluriel lô-z a été aglutinée au singulier...DUR 9885)

Rem. : L'emploi du mot ZIEU au singulier, derrière UN prouve que le Z de la liaison au pluriel est partie integrante du substantif, cf. fr. zyeuter (Hoyer, 1993, p. 210).

A palavra "zieu" começa com Z mesmo no singular, comprovando que a consoante de ligação - $z$ se tornou parte integrante do substantivo: "lô-z ieu" > "un zieu" (fr. les yeux, pt. os olhos). Um fenômeno similar também ocorre no português com a palavra "olho", "olhudo" gerando "zói" e "zoiudo".

Dados do francoprovençal bressan contemporâneos também registram esta ressegmentação. Em (I), a palavra "alanye" (avelã) aparece diante dos artigos indefinidos " $n$ " e "dej" em dados de um falante mais competente (cf. Gomes, 2019). 
Em (J), apresentamos dados de um semi-falante que fornece a palavra "j'alanye" para avelã:

(I) n'alanye, dej alanye (falante competente)

(une noisette, des noisettes)

(J) j’alanye, na j’alanye, de j’alanye (semi-falante)

(noisette, une noisette, des noisettes)

Desta forma, podemos esquematizar em (L) o processo de ressegmentação caracterizado pela aglutinação de -j marca de plural ao substantivo no singular:

(L) n'alanye (uma avelã), dej alanye (umas avelãs) $>$ de j’alanye $>$ na j’alanye, na jalanye

A palavra "jalanye" não foi atestada em dados escritos de Gomes (2019), mas mostrou-se uma evolução possível, sobretudo por manifestar-se entre semi-falantes. Processo semelhante parece ter originado a palavra "joué" (ovo), já dicionarizada na língua, a qual deriva provavelmente de "oué". Vejamos:

(M) l'oué (o ovo), léj oué (os ovos) > lé j’oué > lé joué, lou joué

\section{CONCLUSÃo}

O que se aprende de tudo isso com relação à concordância variável no SN do português brasileiro?

A perda do -s etimológico que ocorre nos nomes (substantivos e adjetivos) do português brasileiro ocorre também em outras línguas ibero-românicas e galoromânicas, e nessas sofre outras mudanças além da supressão tais como sonorização, reanálise, esvaziamento gramatical ressegmentação, não estranhas também ao português brasileiro. Reaparece sob a forma de $-z$ e variantes, o que também não é fenômeno estranho ao português brasileiro em fronteiras de palavras ([uzoגus]). Ou seja, a queda do -s e as mudanças a este vinculadas são fenômenos românicos, que em cada língua, sob condições detalhadas mais específicas, vão engendrar mudanças. É um fenômeno fônico ou morfofonêmico, que acarreta outras mudanças e atua nos casos da concordância de número no $\mathrm{SN}$ do português.

Para tal entendimento, dentro de uma perspectiva que considera que a mudança linguística tem uma direção, contamos com dados originais e confiáveis, baseados em edições que se ativeram a critérios filológicos. Desta forma, amplia-se o encaixamento desta questão: a utilização de dados originais e legítimos contribuíram para um melhor encaixamento do fenômeno do -s de plural envolvido em mudanças na família românica de línguas.

\section{REFERÊNCIAS}

Anglade J. Grammaire de l'ancien provençal ou ancienne langue d'oc: phonétique et morphologie; 1921. [citado 25 jan. 2020]. Disponível em: https://gallica.bnf.fr/ark:/12148/bpt6k255748j.texteImage.

Barra-Jover M. Comment évolue un trait grammatical: le pluriel en français dans une perspective romane. Romance Philology, Brepols Publishers, 2009;63:25-67. [citado 25 jan. 2020]. Disponível em: 
https://www.researchgate.net/publication/32228933 Comment_evolue un trait grammatical le_plu riel en francais dans une perspective romane.

Blanchet P. Parlons provençal: langue et culture. Paris: L'Harmattan; 1999.

Borges Nunes E. Abreviaturas paleográficas portuguesas. Lisboa: FL; 1981.

Bentes AR. Os sefardim e a Hakitía. $2^{a}$.ed.Rio de Janeiro, Mitograph, 1981.

Briançon L. Trois poèmes en patois grenoblois du XVIe siècle. Traduit et présentés par Gaston Tuaillon. Grenoble: Le monde Alpin et Rhodanien; 1/1996.

Chaves E, Alkmim MGR, organizadores. Cartas pessoais do século XIX. Acervo Monsenhor Horta. ICHS, UFOP, Mariana; 2002.

Chaves de Melo G. A língua do Brasil. [1946] 3ª ed., Rio de Janeiro: FGV; 1975.

Chaves E, Martins Ramos J. Abreviaturas no período 1800-1950: nova fonte de pesquisa diacrônica. Cadernos de Estudos Linguísticos, 2015;57(2).

Cohen MAAM. Línguas românicas em extinção: o francoprovençal. In: Ravetti G; Arbex M. (Orgs.) Performance, Exílio, Fronteiras. Belo Horizonte: UFMG; 2002b. p. 265-279.

Cohen MAAM. Reanálise do -s final e o 'drift' românico: o caso do ladino. In: Cohen MAAM, RAMOS JM, organizadoras, Dialeto Mineiro e outras falas. Estudos de variação e mudança linguística. Belo Horizonte: Faculdade de Letras/UFMG; 2002. p. 83-90.

Cohen MAAM. Pelos caminhos de Minas: o português nos manuscritos da Estrada Real. II DIVERMINAS; 22 a 24 de setembro de 2015; Mariana, MG, Brasil. Ouro Preto: UFOP; 2016. Número Especial. Caletroscópio, 2016;4(esp.):8-26. [citado 25 jan. 2020]. Disponível em: https://periodicos.ufop.br/pp/index.php/caletroscopio/article/view/3664.

Cohen MAAM. Reexame de um caso clássico à luz de novos dados: a gramaticalização e a reanálise de -mente. In: Vitral L; Coelho S, organizadores. Estudos de Processos de Gramaticalização em Português. Metodologias e Aplicações. Campinas: Mercado de Letras; 2010.

Duchowny AT, Coelho SM, Coelho GH. Sistema de abreviaturas de documentos adamantinos setecentistas. Revista Letras, 2014;90:233-252. [citado 25 jan. 2020]. Disponível em https://www.researchgate.net/publication/273169001 Sistema de abreviaturas de documentos ada mantinos setecentistas.

Gomes SF. Línguas ameaçadas: o francoprovençal. [tese]. Belo Horizonte: Faculdade de Letras, Universidade Federal de Minas Gerais; 2019. [citado 25 jan. 2020]. Disponível em: http://hdl.handle.net/1843/30845.

Grevisse M. Le bon usage: grammaire française avec des remarques sur la langue française d'aujourd'hui. 6e ed. rev. Gembloux: J. Duculot; 1955.

Harris AC, Campbell L. Historical syntax in cross-linguistic perspective. GB: Cambridge University Press; 1995.

Hoyer G. Textes en dialecte dauphinois: établissement du texte, traduction et analyses linguistiques. [thèse]. Grenoble: Université Sthendal Grenoble III, Centre de Dialectologie; 1993.

Martin JB. Le francoprovençal de poche. Chennevières-sur-Marne: Assimil; 2005.

Mira MHFG. Algumas contribuições para um estudo da fonética, morfologia, sintaxe e léxico da linguagem popular de Lisboa. Licenciatura em Filologia Românica. Lisboa: Faculdade de Letras, 
Universidade de Lisboa; 1954.

Naro A, Scherre MM. Origens do Português Brasileiro. SP: Parábola; 2007.

Prado Mendes ST. Combinações lexicais restritas em manuscritos setecentistas de supla concepção discursiva: escrita e oral [tese]. Belo Horizonte: Faculdade de Letras, Universidade Federal de Minas Gerais; 2008. [citado 25 jan. 2020]. Disponível em http://www.dominiopublico.gov.br/pesquisa/PesquisaObraForm.do?select action=\&co autor=7486 4.

Silva Neto S. Introdução ao Estudo da Língua Portuguesa no Brasil. [1950]. $5^{\text {a }}$ ed. Rio de Janeiro: Presença; 1986.

Tuaillon G. La Dialectologie. In: Pottier B. (ed.) Les sciences du langage en France au XX ème siècle. Peeters, Self; 1991.

Tuaillon G. Trois poèmes grenoblois du XVIe siècle. Grenoble: Care; 1996.

Wartburg WV. La fragmentación lingüística de la Romania. 2ª.ed. Madrid: Gredos; 1971. 